Original Research Article

\title{
Hypertensive disorder of pregnancy and its immediate outcome on neonates in a tertiary care hospital of Western Nepal
}

\author{
Badri Kumar Gupta ${ }^{1 *}$, Amit Kumar Shrivastava ${ }^{2}$, Laxmi Shrestha ${ }^{2}$
}

\author{
${ }^{1}$ Department of Pediatric, \\ ${ }^{2}$ Department of Pharmacology, \\ Universal College of Medical \\ Sciences, Bhairahawa, \\ Rupandehi, Nepal
}

\section{Received: 03 April 2019 \\ Revised: 12 April 2019 \\ Accepted: 03 May 2019 \\ *Correspondence to: \\ Dr. Badri Kumar Gupta, Email: drbadrikrgupta@ gmail.com}

Copyright: (C) the author(s), publisher and licensee Medip Academy. This is an openaccess article distributed under the terms of the Creative Commons Attribution NonCommercial License, which permits unrestricted noncommercial use, distribution, and reproduction in any medium, provided the original work is properly cited.

\begin{abstract}
Background: Hypertensive disorders in pregnancy remain a major cause of maternal and neonatal morbidity and mortality worldwide. This study prospectively examined the immediate neonatal outcome of women with maternal hypertensive disorder of pregnancy (HPD).

Methods: This is a prospective study conducted at NICU in Universal College of Medical Sciences Hospital over a period from $2^{\text {nd }}$ February 2018 to $1^{\text {st }}$ February 2019. Fifty-two mothers and their newborn were selected. Mothers with gestational hypertension, preeclampsia, and preeclampsia superimposed on chronic hypertension and chronic hypertension were included.

Results: Mean maternal age was 26.4 years. Mean gestational age was $34 \pm 4$ weeks. 38 were male and 24 were female with male: female ratio 1.72:1. Thirty seven $(71.2 \%)$ mothers needed lower uterine caesarian section, fourteen $(26.9 \%)$ mothers delivered NVD and one (1.9\%) forceps delivery. Low birth weight $(<2.5 \mathrm{~kg})$ babies were $25(48.1 \% \%)$, very low birth weight $(<1.5 \mathrm{~kg})$ were 9 $(17.3 \%)$ and normal weight were $18(34.3 \%)$. Intrauterine growth retardation (IUGR) were $18(30 \%)$. Perinatal asphyxia $10(19.2 \%)$ were most common cause of admission, other cause of admission were sepsis and prematurity.

Conclusions: Eclampsia is still a common and serious complication of pregnancy. Proper antenatal care, detection of preeclampsia with early management and timely referral of high risk patient, administered of $\mathrm{MgSO}_{4}$ in correct doses and properly timed caesarean section in selected cases would reduce the incidence of eclampsia associated maternal and perinatal morbidity and mortality in our facility.
\end{abstract}

Keywords: Anti-hypertensive drugs, Gestational hypertension, Hypoxia, Hypertension, Maternal hypertension disorder of pregnancy, Preeclampsia

\section{INTRODUCTION}

Hypertensive disorders of pregnancy have remained a significant public threat in both developed and developing countries, contributing globally to maternal and perinatal morbidity and mortality. ${ }^{1,2}$ In India, the incidence of this threatening condition was $5.38 \%$. $^{3}$

Majority of fetal complications occur due to prematurity and hypoxia. ${ }^{4,5}$ fetal complications are related to the severity of preeclampsia, duration of the disease and degree of proteinuria. ${ }^{6}$
Pregnancy-related hypertension (PHTN) syndromes are a frequent and potentially deadly complication of pregnancy, while also negatively impacting the lifelong health of the mother and child. PHTN appears in women likely to develop hypertension later in life, with the stress of pregnancy unmasking a subclinical hypertensive phenotype. ${ }^{7}$ However, distinguishing between PHTN and chronic hypertension is essential for optimal management. Preeclampsia (PE) is linked to potentially severe outcomes and lacks effective treatments due to poorly understood mechanisms. Inadequate remodelling of spiral uterine arteries (SUAs), the cornerstone of PE pathophysiology, leads to hypoperfusion of the developing placenta. $^{8}$ In 
normal pregnancies, extravillous trophoblast (EVT) cells assume an invasive phenotype and invade SUAs, transforming them into large conduits. Decidual natural killer cells play an essential role, mediating materno-fetal immune tolerance, inducing early SUA remodeling and regulating EVT invasiveness. Notch signalling is important in EVT phenotypic switch and is dysregulated in PE. ${ }^{9}$ The hypoxic placenta releases antiangiogenic and proinflammatory factors that converge upon maternal endothelium, inducing endothelial dysfunction, hypertension, and organ damage. Hypoxia-inducible factor $1-\alpha$ is upstream of such molecules, whereas endothelin-1 is a major effector. ${ }^{10} \mathrm{We}$ also describe important genetic links and evidence of incomplete materno-fetal immune tolerance, with PE patients presenting with autoantibodies, lower Treg, and higher Th17 cells. ${ }^{11}$ Thus, PE manifestations arise as a consequence of mal-placentation or/and because of a predisposition of the maternal vascular bed to excessively react to pathogenic molecules. From this pathophysiological basis, we provide current and propose future therapeutic directions for PE. ${ }^{12}$ Spasm of the uteroplacental circulation leads to fetal distress, accidental haemorrhage, IUGR, IUD, low birth weight, low APGAR score, NICU admissions and early neonatal death. ${ }^{13}$ Perinatal morbidity is increased due to spontaneous preterm labour or iatrogenic preterm induction. Hypertensive disorders of pregnancy (HDP) is the most common complication and seriously endanger the safety of the mother and the fetus during pregnancy as well as continue its impact on neonatal period. ${ }^{14} \mathrm{HDP}$ is a multiorgan, heterogeneous disorder of pregnancy associated with significant maternal and neonatal morbidity and mortality. In some circumstances, delivery is needed to halt its progression for the benefit of the mother, fetus and for the neonate. ${ }^{15}$

The most widely accepted definition and classification of hypertensive disorders of pregnancy was proposed by the National High blood Pressure Education Program (NHBPEP) Working, which used a blood pressure of $140 / 90 \mathrm{mmHg}$ or higher on two separate occasions at least 4 hours apart as the diagnostic criterion. ${ }^{16}$

The classification of high blood pressure in pregnancy are as follows.

- Gestational hypertension: hypertension manifested after 20 weeks of gestation.

- Pre-eclampsia (PE)/Pre-eclamtic toxaemia (PET): Hypertension associated with proteinuria greater than $0.3 \mathrm{~g}$ in a twenty four hour urine collection or greater than $1 \mathrm{~g} / \mathrm{L}$ in a random sample.

- Essential hypertension: The presence of sustained blood pressure of 140/90 mm Hg or higher before pregnancy or before twenty weeks of gestation.

- Pre-eclampasia superimposed on essential hypertension (HTN): Pre-eclampasia diagnosed in a previously hypertensive women. ${ }^{1}$
This classification by National High Blood pressure Education Program Working Group. ${ }^{13}$

Eclampsia: Pre-eclampsia when complicated with convulsion and/or coma.

The term pregnancy induced hypertension (PIH) is defined as the hypertension that develops as a direct result of the gravid state. It includes (i) Gestational hypertension (ii) Pre-eclampasia (iii) Eclampsia. ${ }^{14}$

Ten percent of the pregnancy was complicated with hypertensive disorders of pregnancy. Among them $90 \%$ was due to gestational hypertension and PE. ${ }^{15}$ Moreover, preeclampsia produces potentially lethal complications including placental ablation, disseminated intravascular coagulation, intracranial hemorrhage, hepatic failure, acute renal failure, and cardiovascular collapse. IUGR, intrauterine fetal demise are the other related obstetric problems were observed among these mother. ${ }^{16}$ The offspring of women with hypertension during pregnancy experience higher rates of prematurity and low birth weight compared to healthy maternal controls. Other medical problems like respiratory distress syndrome (RDS), transient tachypnea of the neonate (TTN), persistent pulmonary hypertension (PPHN) and respiratory failure observed in late preterm neonates (3436 weeks) specially with maternal history severe preeclampsia. ${ }^{17}$ Special neonatal care is required for such baby which is associated with emotional and financial stress for both parents and third party payers and long-term developmental consequences. ${ }^{18}$

\section{METHODS}

This is a prospective study conducted at NICU in Universal College of Medical Sciences Hospital over a period from $2^{\text {nd }}$ February 2018 to $1^{\text {st }}$ February 2019.

\section{Inclusion criteria}

There were 52 neonates with their maternal history of hypertensive disorder during pregnancy, like gestational hypertension, preeclampsia, eclampsia, patient or essential hypertension were selected for the study. Both inpatient and outpatient mothers with regular antenatal check-up (ANC) with good documentation regarding maternal physical condition, regular documentation of blood pressure with antihypertensive medication and documentation of condition of the fetus were included for the study.

This study was done to evaluate immediate outcome of admitted neonates. Data regarding the demographic parameter of the mother like Antenatal checkup, gestational age (determine by last menstrual period or $1^{\text {st }}$ trimester ultrasound) type of maternal hypertensive disorder of pregnancy, obstetric problems like preterm labour, mode of delivery were recorded in structured questionnaire. 
Neonatal parameters were sex, gestational age, birth weight and the neonatal medical problems like respiratory distress syndrome, congenital pneumonia, meconium as piration syndrome, perinatal asphyxia with convulsion were also recorded.

Investigation were complete blood count and blood culture, serum electrolytes were done, abnormal coagulation profile was assessed by prothrombin time and partial thromboplastintime. ${ }^{19}$

\section{Exclusion criteria}

Mothers with infant of diabetic mother (IDM),gestational mellitus(GDM), and chronic diseases like chronic renal failure, chronic liver disease, and endocrine diseases, collagen disease, and mothers with raised blood pressure observed in only last one or two visit at term and babies with definite congenital malformation, metabolic disorder, and any syndrome wereexcludedfromthestudy. ${ }^{20}$

The approval of Institutional Review Committee of Universal College of Medical Sciences, Bhairahawa, Nepal was taken before the initiation of experiment. Registration No. UCMS/IRC/031/18. All the protocols and experiments were conducted in compliance with the ethical principles and guidelines.

\section{Statistical analysis}

The data was analyzed by using SPSS version 20.0.

\section{Management of hypertension}

Fetal monitoring consisted of DFMC, FHR monitoring, NST, umbilical and cerebral Doppler. USG was done for the fetal weight, serial growth, AFI, BPP, placental location and maturity.

Treatment included rest, dietary changes, and control of blood pressure by using antihypertensive (methyl dopa, labetalol or nifedipine) and obstetric management. In patients of eclampsia, treatment was given for control of $\mathrm{BP}$, control of seizures by anticonvulsants (mgso 4 was used as the anticonvulsant of choice and Pritchard regimen was followed: $4 \mathrm{~g}$ of $25 \% \mathrm{MgSO}_{4} \mathrm{I}$.V was given slowly over 5-10 minutes and $5 \mathrm{gm}$ of $50 \% \mathrm{MgSO}_{4} \mathrm{I} . \mathrm{M}$ was given into each buttock followed by $5 \mathrm{gm} 50 \% \mathrm{MgSO}_{4}$ I.M 4 hrly in alternate buttock) and control of complications. Ultimately pregnancy was terminated and delivery was conducted.

In mild preeclampsia and gestational hypertension termination of pregnancy was done by inducing labour at 37 weeks at this gestational age, the maternal and fetal risks during expectant management clearly out weight potential benefits to fetus. In patients $<37$ weeks of gestation, termination of pregnancy was warranted only if maternal condition deteriorated or if there was fetal compromise. $^{21,22}$
Pregnancy was terminated by LSCS for urgent termination for maternal shake as in acute fulminating preeclampsia and eclampsia when cervixes was not ripe and also for fetal sake when fetus was in jeopardy as indicated by deranged Dopper studies (revers diastolic flow), severe IUGR, meconium staining of liquor or fetal distress. ${ }^{23}$

\section{RESULTS}

Total 52 mothers with their neonates were selected for the study. Mean maternal age was 24.96years. Mean gestational age was $37+5$ weeks. Nine $(15 \%)$ needed ventilator care and $6(10 \%)$ needed nasal continuous positive airway pressure (NCPAP) for respiratory problem. $6(10 \%)$ babies were expired and 54(90\%) survived.

Table 1: Maternal demographic profile.

\begin{tabular}{|lll|}
\hline $\begin{array}{l}\text { Demographic } \\
\text { profile }\end{array}$ & Frequency & $\begin{array}{l}\text { Percentage } \\
(\%)\end{array}$ \\
\hline Cast & 52 & 100 \\
\hline Hindu & 38 & 73.1 \\
\hline Muslim & 14 & 26.9 \\
\hline Age & & \\
\hline $20-25$ & 31 & 59.6 \\
\hline $26-30$ & 17 & 32.7 \\
\hline $31-35$ & 3 & 5.8 \\
\hline$>35$ & 1 & 1.9 \\
\hline Locality & & \\
\hline Rural & 32 & 61.5 \\
\hline Urban & 30 & 38.5 \\
\hline
\end{tabular}

Table 2: Other neonatal delivery techniques.

\begin{tabular}{|lll|}
\hline $\begin{array}{l}\text { Neonatal delivery } \\
\text { techniques }\end{array}$ & Frequency & Percentage \\
\hline LCSC & 37 & 71.2 \\
\hline NVD & 14 & 26.9 \\
\hline Forceps & 1 & 1.9 \\
\hline Consanguity & 4 & 7.7 \\
\hline
\end{tabular}

Table 1 and Table 2 demonstrates demographic characteristics of patient. Eclampsia were more common in the age group 20 to 25 yrs group (59.6\%) and rural areas $(61.5 \%)$ In this study $37(71.2 \%)$ needed lower uterine caesarian section (LSCS) for delivery and normal vaginal delivery $14(26.9 \%)$ and $1(1.9 \%)$ forceps delivery. $38(73.1 \%)$ were Hindu 14(26.9) were Muslim among which $4(7.7 \%)$ were have consanguity marriage.

Table 3 representing the maternal hypertension there are the various ranges of hypertension and $26.9 \%$ patent presented with severe hypertension with BP>160/110, $57.7 \%$ patient had BP between 140/90-159/109 and $15.4 \%$ patient had BP $<140 / 90$.

Table 4 showed the neonatal gestational age total no of patients are $n=52$ Majority of patient $n=37(71.2 \%)$ 
presented as gestational age $>37$ weeks, $\mathrm{n}=10(19.2 \%)$ patient between 32-36 weeks and $n=5(9.6 \%)$ at $<32$ weeks.

Table 3: Types of maternal hypertensive disorder.

\begin{tabular}{|llll|}
\hline \multicolumn{2}{|l}{ Types of B.P. } & No. of Cases & Percent \\
\hline Systolic & Diastolic & & 15.4 \\
\hline$<140$ & 90 & 8 & 57.7 \\
\hline $140-159$ & $90-109$ & 30 & 26.9 \\
\hline$>160$ & $>110$ & 14 & \\
\hline
\end{tabular}

Table 4: Distribution of neonates according to gestational age.

\begin{tabular}{|lll|}
\hline $\begin{array}{l}\text { Distribution of } \\
\text { neonates } \\
\text { (gestational age) }\end{array}$ & $\begin{array}{l}\text { No. of } \\
\text { Neonates }\end{array}$ & Percentage \\
\hline$<32$ weeks & 5 & 9.6 \\
\hline $32-36$ weeks & 10 & 19.2 \\
\hline $37-42$ weeks & 37 & 71.2 \\
\hline
\end{tabular}

Table 5: Distribution of neonates according to birth weight.

\begin{tabular}{|lll|}
\hline Birth Weight & $\begin{array}{l}\text { No. of } \\
\text { neonates }\end{array}$ & $\%$ \\
\hline Low Birth weight $(1.5-2.5 \mathrm{~kg})$ & 25 & 8.1 \\
\hline Very low birth weight $(1-1.5 \mathrm{~kg})$ & 9 & 17.3 \\
\hline Normal birth weight $(2.5 \mathrm{~kg}$ or more $)$ & 18 & 34.6 \\
\hline LGA & 0 & 0 \\
\hline IUGR & 17 & 32.69 \\
\hline
\end{tabular}

Table 5 representing the birth weight of neonates $n=52$ divided into according to their weight, low birth weight $\mathrm{n}=$ $25(48.1 \%)$, very low birth weight $n=9(17.3 \%)$, normal birth weight $\mathrm{n}=18(34.6 \%)$, LGA is zero and IUGR $\mathrm{n}=17$ (32.69).

\section{Neonatal clinical problems at the time of admission}

This study showed that various neonatal clinical problems at the time of administration as per the given data perinatal asphyxia were the most common cause or administration of neonates, that is total 10 cases $19.2 \%$ were present other comorbidities like sepsis, prematurity, hypoglycemia, RDS, HIE, polythermia, IVH apnea of prematurity MAS, neonatal seizure, hypothermia were also recorded. In which maximum cases were sepsis and prematurity, each is 7 cases that is $(13.5 \%)$, followed by hypoglycemia and RDS each of cases were present (that is $7.7 \%$ ) and 3 cases of HIE and polythermia were recorded. $5.8 \%$ and a case of hypothermia and congenital heart disease were also present (each $1 \%$ ) and 5 other cases were also present which contributes $5.8 \%$ of total.

Figure 1 showed the percentage of neonatal clinical problems. Perinatal asphyxia were the most common cause for admission. Other comorbidies were prematurity, sepsis, hypoglycemia, and respiratory distress.

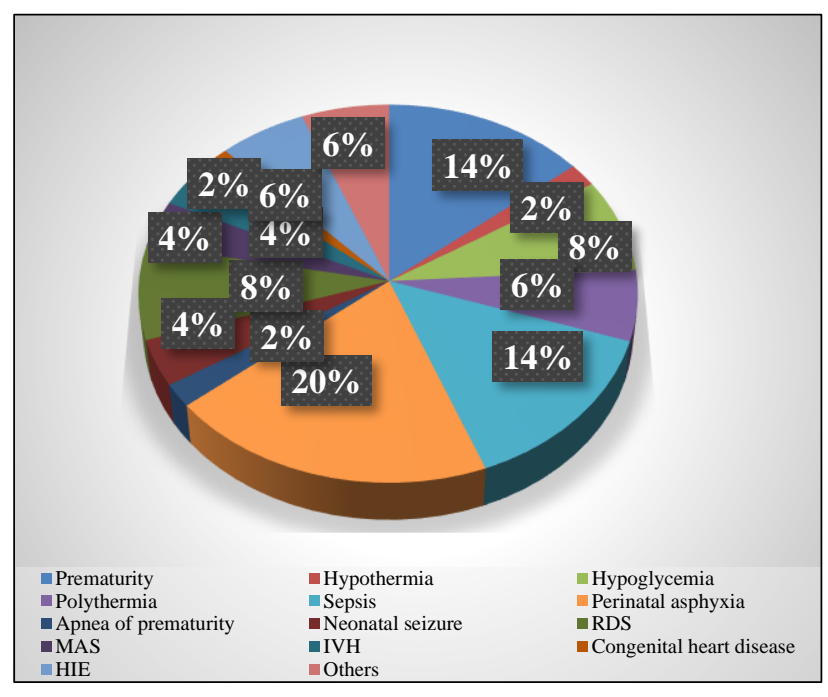

Figure 1: Neonatal clinical problems.

The study showed the fatal outcome at birth conducted among months of hypertension disorder at birth by using two different elements/outcome those are number of alive cases and no. of neonatal death cases among the total study subjects $\mathrm{n}=52$ alive cases among the study subjects $\mathrm{n}=41$ $(78.8 \%)$ and the total neonatal death among study subjects is $n=11(21.2 \%)$ of the total (Table 7).

Table 7: Fetal outcome at birth among study subjects.

\begin{tabular}{|lll|}
\hline Outcome & No. of Cases & Percentage \\
\hline Alive & 41 & 78.8 \\
\hline Neonatal death & 11 & 21.2 \\
\hline Total & 52 & 100 \\
\hline
\end{tabular}

\section{Meconium stained liquor}

Here the study of liquor conducted among 52 cases shows there were total 13 out of 52 cases were present with meconium stained liquor $(25 \%)$ and 39 cases out 52 there were no meconium stained liquid (that is $75 \%$ ).

\section{DISCUSSION}

Worldwide hypertensive disorders of pregnancy have been identified as a major health problem associated with increased perinatal morbidity and mortality. Various authors have found the frequency of hypertensive disorders of pregnancy between 7-10\%. ${ }^{24,25}$ Among them gestational hypertension was $46 \%$, pre-eclamtic toxemia $45 \% .{ }^{26}$ In our study gestational hypertension $30(57.7 \%)$ was the major hypertensive disorder of pregnancy and PET was $14(26.9 \%)$.

In this study, 37(71.2\%) neonates were delivered by LSCS and $14(26.9 \%)$ delivered by NVD. In other study operative 
delivery were reported to be increased in hypertensive disorders of pregnancies as seen in another 10 study.

Hypertensive disorders of pregnancy predispose women to acute or chronic utero-placental insufficiency, resulting in ante or intra-partum hypoxia even anoxia that may lead to fetal death. ${ }^{27}$ Perinatal outcome is strongly influenced by gestational age and the severity of hypertension as expressed by the need for antihypertensive treatment, irrespective of the underlying syndrome. ${ }^{28,29}$

So, fetal growth is a useful marker for fetal well-being. ${ }^{30,31}$ Pregnancies complicated by intrauterine growth restriction (IUGR), defined as a pathological process of reduced fetal growth, have been associated with increase in perinatal mortality. ${ }^{32,33}$ A high incidence of IUGR/SGA infants in women who have PE has been reported, ranging from $15 \%$ to more than $50 \% .{ }^{34,35}$ Intrauterine growth retardation was $17(32.60 \%)$ in our study. Low birth weight baby was $25(48.1 \%)$ and very low birth weight baby $9(17.3 \%)$ in this study. Therefore total $34(65.4 \%)$ neonates were $<2.5 \mathrm{~kg}$.

Another problem is preterm delivery with maternal hypertensive disorder of pregnancy. Epidemiologic studies have reported alarmingly high rates of preterm births, predominantly due to preeclampsia. In our study, preterm (<32 weeks) were 5(9.6\%), near term neonates $(32-36$ weeks) were $10(19.2 \%)$, so total $15(28.2 \%)$ delivered before 36 weeks. Term neonates (37-42 weeks) were $37(71.2 \%)$. The percentage of term and low birth weight babies were high in this study.

Neonates needed admission for other than intrauterine growth retardation and/or preterm delivery, were due to complications like perinatal asphyxia were 10(19.2\%), sepsis $7(13.5 \%)$, respiratory distress $4(17.7 \%)$.

No difference in incidence of lung maturity was seen in different studies with or without the history of maternal hypertensive disorder of pregnancy or PE. ${ }^{36}$ Out of 52neonates $41(78.8 \%)$ were discharge and $11(21.2 \%)$ neonates were expired.

Respiratory distress 30(50\%) were most common cause of admission, other associated problems were perinatal asphyxia (PNA) with seizure and meconium aspiration syndrome and to rule out sepsis in suspected cases. Nine (15\%) needed ventilator care and 6(10\%) needed nasal continuous positive airway pressure (NCPAP) for respiratory problem. $6(10 \%)$ babies were expired and 54(90\%) survived. Average hospital stay was 18.32(+$10.68)$ days with a highest hospital stay of 49 days and the lowest 4 days.

\section{CONCLUSION}

Maternal hypertensive disorder of pregnancy (HDP) is associated with neonatal mortality and the morbidity which is observed in this study. Significant number of babies were delivered by caesarian section and needed hospitalization.
This is a major obstetric problem has a variable degrees of neonatal involvement, we observed mean birth weight, mean gestational age was less, IUGR was high in admitted group than that of the non-admitted group. Eclampsia is still a common and serious complication of pregnancy. Proper antenatal care, detection of preeclampsia with early management and timely referral of high risk patient, administered of $\mathrm{MgSO}_{4}$ in correct doses and properly timed caesarean section in selected case would reduce the incidence of eclampsia associated maternal and perinatal morbidity and mortality in our facility.

\section{ACKNOWLEDGEMENTS}

Authors would like to thank the department of Obstetrics and Gynecology and Neonatal intensive Care Unit of Universal College of Medical Sciences Bhairahawa, Nepal.

Funding: No funding sources

Conflict of interest: None declared

Ethical approval: The study was approved by the Institutional Review Committee of Universal College of Medical Sciences, Bhairahawa, Nepal (UCMS/IRC/031/18)

\section{REFERENCES}

1. Shah A, Fawole B, M'Imunya JM, Amokrane F, Nafiou I, Wolomby JJ, et al. Cesarean delivery outcomes from the WHO global survey on maternal and perinatal health in Africa. Inter J Gynecol Obst. 2009;107(3):191-7.

2. McClure EM, Saleem S, Pasha O, Goldenberg RL. Stillbirth in developing countries: a review of causes, risk factors and prevention strategies. J Maternal-Fetal Neonatal Med. 2009;22(3):183-90.

3. Prakash J, Pandey LK, Singh AK, Kar B. Hypertension in pregnancy: hospital based study. J Assoc Physicians India. 2006;54:273-8.

4. Hutter D, Jaeggi E. Causes and mechanisms of intrauterine hypoxia and its impact on the fetal cardiovascular system: a review. Inter J Pediatr. 2010 Oct 19;2010.

5. Backes CH, Markham K, Moorehead P, Cordero L, Nankervis CA, Giannone PJ. Maternal preeclampsia and neonatal outcomes. J Pregnancy. 2011;2011:1-7.

6. Hofmyr GJ, Belfort M. proteinuria as a predictor of complication of pre-eclemsia. BMC Medline. 2009;7:11.

7. Vest AR, Cho LS. Hypertension in pregnancy. Curr Atheroscler Rep. 2014;16:395.

8. American College of Obstetricians and Gynecologists. Task Force on Hypertension in Pregnancy. Hypertension in pregnancy. Report of the American College of Obstetricians and Gynecologists' Task Force on Hypertension in Pregnancy. Obstet Gynecol. 2013;122:1122-31.

9. Bartsch E, Medcalf KE, Park AL, Ray JG. Clinical risk factors for pre-eclampsia determined in early 
pregnancy: systematic review and meta-analysis of large cohort studies. BMJ. 2016 Apr 19;353:i1753.

10. Pijnenborg R, Vercruysse L, Hanssens M. The uterine spiral arteries in human pregnancy: facts and controversies. Placenta. 2006;27:939-58.

11. Smith SD, Dunk CE, Aplin JD, Harris LK, Jones RL. Evidence for immune cell involvement in decidual spiral arteriole remodeling in early human pregnancy. American J Pathol. 2009 May 1;174(5):1959-71.

12. Palei AC, Spradley FT, Warrington JP, George EM, Granger JP. Pathophysiology of hypertension in preeclampsia: a lesson in integrative physiology. Acta Physiologica. 2013 Jul;208(3):224-33.

13. Gifford RW. Report of the national high blood pressure education program working group on high blood pressure in pregnancy. Am J Obstet Gynecol. 2000;183:S1-5.

14. Datta's DC. Hypertensive disorder of pregnancy. Hirala Kona. Editor. Textbook of obstetrics. 17th Ed. New central Book Agency Limited; 2011;219-220.

15. Roberts CL, Algert CS, Morris JM, Ford JB, Henderson-Smart DJ. Hypertensive disorders in pregnancy: a population based study. MJA. 2005; 182:332-5.

16. Tranquilli AL, Giannubilo SR. The weight of foetal growth restriction in 437 hypertensive pregnancies. Arch Gynecol Obstet. 2004;270:214-6.

17. Dudell GG, Jain L. Hypoxic respiratory failure in the late preterm infant. Clinics Perinatol. 2006 Dec 1;33(4):803-30.

18. Markestad T, Vik T, Ahlsten G, Gebre-Medhin M, Skjærven R, Jacobsen G, et al. Small-for-gestationalage (SGA) infants born at term: growth and development during the first year of life. Acta obstetricia et gynecologica Scandinavica. Supplement. 1997;165:93-101.

19. Deorari AK, Arora NK, Paul VK, Singh M. Perinatal outcome in hypertensive disease of pregnancy. Indian Pediatr. 1985;22:877-81.

20. Joshi N, Pandit SN, Shah PK, Vaidya PR. A study of pre-eclampsia to xemia in pregnancy. Indian J Obstet Gynecol. 1990;40:506-9.

21. Sibai BM. Antihypertensive drugs during pregnancy. Semin Perinatol. 2001;25:159-64.

22. Chobanian AV, Bakris GL, Black HR, Cushman WC, Green LA, Izzo JL Jr, et al. The Seventh Report of the Joint National Committee on Prevention, Detection, Evaluation, and Treatment of High Blood Pressure: the JNC 7 report. Hypertension. 2003;42:1206-52.

23. Levine RJ, Lam C, Qian C, Yu KF, Maynard SE, Sachs BP, et al. Urinary placental growth factor and risk of preeclampsia. JAMA. 2005;293:77-85.

24. Roberts CL, Algert CS, Morris JM, Ford JB, Henderson-Smart DJ. Hypertensive disorders in pregnancy: a population-based study. MJA. 2005; 182:332-5.
25. Goften EN, Capewe IV, Natale R, Gratton RJ. Obstetric al intervention rates and maternal and neonatal outcomes of women with gestational hypertension. Am J Obstet Gynecol. 2001;185:798803.

26. Habli M, Levine RJ, Qian C, Sibai B. Neonatal outcomes in pregnancies with preeclampsia or gestational hypertension and in normotensive pregnancies that delivered at 35,36 , or 37 weeks of gestation. American J Obstetrics Gynecol. 2007 Oct 1;197(4):406-e1.

27. Saftlas AF, Olson DR, Franks AL, Atrash HK, Pokras R. Epidemiology of preeclampsia and eclampsia in the United States, 1979-1986. Ame J Obstetrics Gynecol. 1990 Aug 1;163(2):460-5.

28. Aucott SW, Donohue PK, Northington FJ. Increased morbidity in severe early intrauterine growth restriction. J Perinatol. 2004 Jul;24(7):435.

29. Richardus JH, Graafmans WC, Verloove-Vanhorick SP, Mackenbach JP. Differences in perinatal mortality and suboptimal care between 10 European regions: results of an international audit. BJOG: An Inter J Obst Gynaecol. 2003 Feb 1;110(2):97-105.

30. Ray JG, Burrows RF, Burrows EA, Vermeulen MJ. Outcome study of hypertension in pregnancy. Early Hum Dev. 2001;64:129-43.

31. Sibai B, Dekker G, Kupferminc M. Pre-eclampsia. Lancet. 2005;365:785-99.

32. Yadav S, Saxena U, Yadav R, Gupta S. Hypertensive disorders of pregnancy and maternal and fetal outcome: A case controlled study. J Indian Med Assoc. 1997;95:548-6551.

33. Sibai BM. Eclampsia: VI. Maternal perinatal outcome in 254 consecutive cases. Am J Obstet Gyneocol. 1990;163:1054-5.

34. Schiff E, Friedman SA, Mercer BM, Sibbai BM. Fetal lung maturity is not accelerated in pre eclamptic pregnancies. Am J Obstet Gynecol. 1993;169:1096101.

35. Silveira RC, Procianoy RS, Koch AS, Benjamin AC, Schindwein AF. Growth and neuro development outcome of very low birth weight infants delivered by preeclamptic mothers. Acta Paediatr. 2007;96:173842.

36. Bashiri A, Zmora E, Sheiner E, Hershkovitz R, Shoham-VardiI, Mazor M. Maternal hypertensive disorders are an independent risk factor for the development of necrotizing enterocolitis in very low birth weight infants. Fetal Diagn Ther. 2003;18:404-7.

Cite this article as: Gupta BK, Shrivastava AK, Shrestha L. Hypertensive disorder of pregnancy and its immediate outcome on neonates in a tertiary care hospital of Western Nepal. Int J Basic Clin Pharmacol 2019;8:1343-8. 